\title{
Commentary: Blurring Borders: Innate Immunity with Adaptive Features
}

\author{
Edwin L. Cooper* \\ Laboratory of Comparative Immunology, Department of Neurobiology, David Geffen School of Medicine, University of \\ California, Los Angeles, Los Angeles, CA, USA
}

Keywords: blurring, earthworm, innate, immune, memory

\section{A commentary on}

Blurring Borders: Innate Immunity with Adaptive Features

by Kvell, K., Cooper, E. L., Engelmann, P., Bovari, J., and Nemeth, P. (2007). Clin. Dev. Immunol. 2007:83671. doi: 10.1155/2007/83671

\section{OPEN ACCESS}

Edited by:

Humberto Lanz-Mendoza, Instituto Nacional de Salud Pública,

Mexico

Reviewed by:

Jorge Contreras-Garduño, Escuela Nacional de Estudios

Superiores, Unidad Morelia, Universidad Nacional Autónoma de México, Mexico

*Correspondence:

Edwin L. Cooper cooper@mednet.ucla.edu

Specialty section:

This article was submitted to

Microbial Immunology,

a section of the journal

Frontiers in Microbiology

Received: 10 November 2015 Accepted: 07 March 2016

Published: 24 March 2016

Citation:

Cooper EL (2016) Commentary: Blurring Borders: Innate Immunity with Adaptive Features.

Front. Microbiol. 7:358. doi: 10.3389/fmicb.2016.00358
Adaptive immunity is now being deconstructed to encompass less stringent rules including initiation, and actual effector activity. Expanding the repertoire of invertebrate innate immunity has greatly facilitated a search for what actually constitutes innate and adaptive. Strict definitions become blurred casting skepticism on using rigid definitions that define innate and adaptive immunity (Kvell et al., 2007). Immunology has experienced commendable growth. Immutable tenets deserve a brief mention. First, there is a need to limit strict divisions of adaptive and innate immunity. Second, to open these two views allows extended inclusions, reveals essential merits of innate immunity and admits inclusive invertebrate characteristics. We can even include features of adaptive responses especially to danger (Pradeu and Cooper, 2012). To facilitate this emerging reality recognizes hazy characteristics that fade into each other- that blur; they are neither black nor white but a "clear gray"-reminiscent of impressionist paintings (Cooper, 2010, 2012).

Blurring of immune responses has been confirmed as a distinct but related viewpoint. Removed from the pervasive $\mathrm{T}$ and $\mathrm{B}$ cell paradigm putative NK cells function in complex invertebrates (e.g., earthworms). For immunology during its youth, it was the NK cell that augmented intellectual understanding of immunity (Paust and von Andrian, 2011). Still perpetual bias prevailed, even ignoring immune response complexity in other vertebrates (fish, amphibians, reptiles, birds) and perforce invertebrates! The raison d'etre for having evolved an immune response relegated functions akin to distinguishing self not self especially to external pathogens. But then the question arose questioning equally threatening internal threats, i.e., cancer. Predictably existence or lack of cancer may emerge as the last frontier as immunology perseveres.

Turning to a well-known invertebrate model, earthworm transplantation immunity is crucial. Xenografts from different genera are rejected suggesting responses that (1) mobilize immune clones; (2) react specifically against non-self antigens and retain memory (Cooper, 1969; Hostetter and Cooper, 1973). Clones may develop locally or be recruited and blurred. Responses from danger signals may emanate from inflamed sites (Lemmi and Cooper, 1981; Pradeu and Cooper, 2012). Recipients of sensitized (immune, primed) coelomocytes reject test grafts more rapidly than controls, shorter than earthworms injected with leukocytes from unsensitized worms (Bailey et al., 1971). Memory is short lived, and occurs only if repeat grafts are transplanted before 10 days after the first immunizing grafts (Lemmi and Cooper, 1981; Cooper and Roch, 1986; Engelmann et al., 2011. Coelomocytes mediate rejection; tritiated thymidine $\left({ }^{3} \mathrm{HTdR}\right)$ incorporates only into DNA 


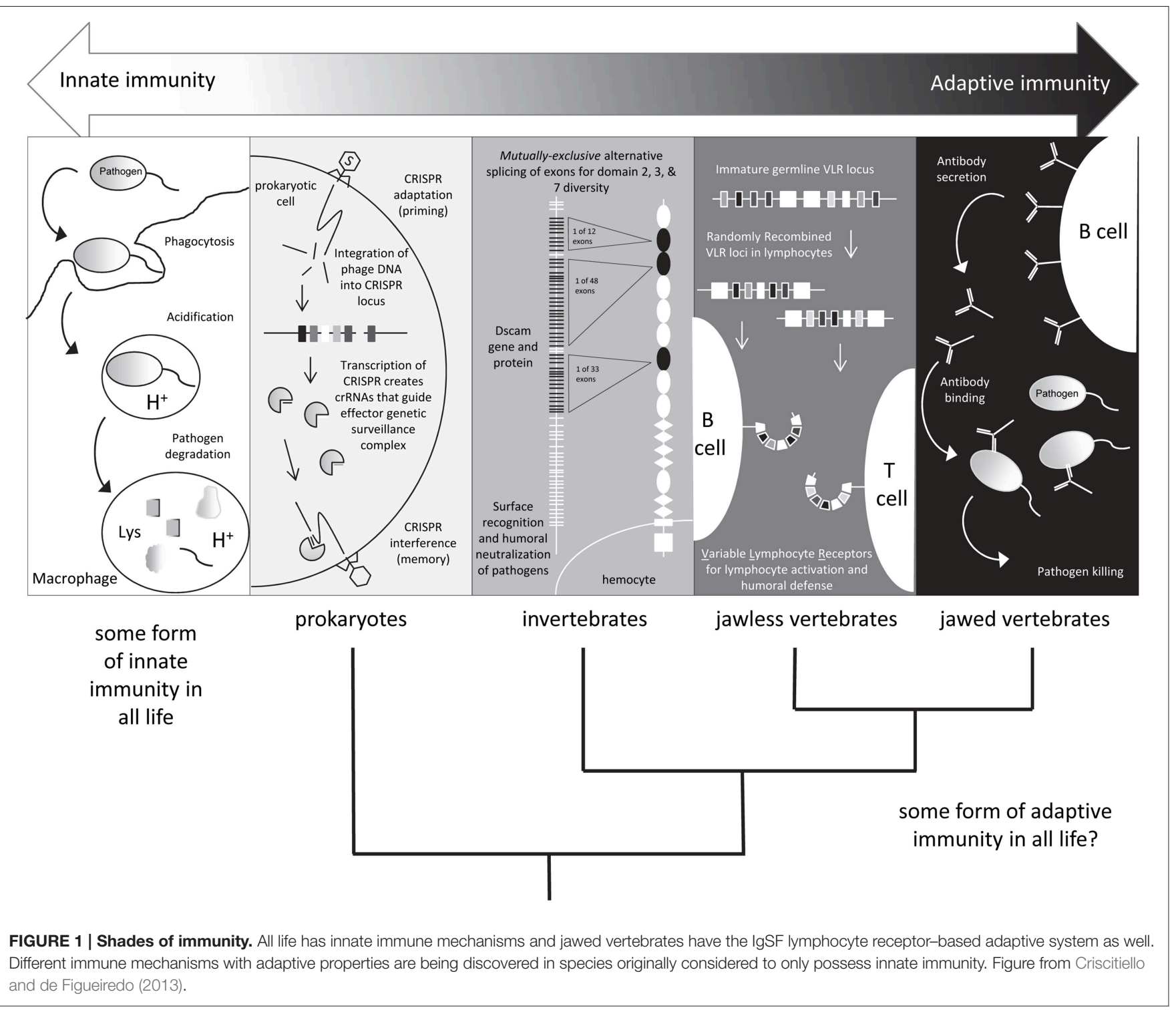

of dividing cells. Coelomocytes divide or may be recruited after exposure to foreign antigen (Cooper and Roch, 1984). Recognition of, binding to, and killing foreign cells in a natural killer cell-like reaction reflects natural immunity (Cooper et al., 1995). Difference in responses between autogeneic and allogeneic effector cells may reflect interclonal immunologic rivalry causing blurring between incompatible effectors.

Earthworm coelomocytes (leukocytes) in vitro affect cytotoxicity against the NK-sensitive, human tumor cell line, K562, and the NK-resistant targets (U937, BSM, CEM). By cytofluorimetric analyses using mouse anti-human monoclonal antibodies, two coelomocyte types are: (1) small (8-11 micron) electron-dense cells (SC): CD11a+, CD45RA+, CD45RO+, CDw49b+, CD54+, beta 2-m+ and Thy-1+; (2) large (12-15 micron) electron-lucent cells (LC); they are negative for these markers, and for other CD and MHC class I and class II markers. SC are active during recognition, rapidly binding to targets; LC are phagocytic. Release of $51 \mathrm{Cr}$ revealed rapid, significant, and equal levels of killing; primitive NK-like activity evolved early (Cossarizza et al., 1996). This represents the first definition of distinction between cell killing and phagocytosis, so often misunderstood in invertebrate systems. Although $\mathrm{T}$ cells and $\mathrm{B}$ cells are absent in earthworms there is substantial evidence indicative of NK-like cells.

Natural killer (NK) cells are effector lymphocytes of innate immunity endowed with cytolytic functions. NK cells express a repertoire of activating and inhibitory receptors calibrated to ensure self-tolerance while allowing assaults against viral infection and tumor development. However, NK cells show no invariant response but rather adapt to their environment. Analyses unveil that NK cells mount a form of antigen-specific immunologic memory (Kurtz, 2005; Little et al., 2005). NK cells thus exert sophisticated biological functions attributable to innate and adaptive immunity, blurring any functional borders between these two arms of the immune response (Vivier et al., 2011). Attention is focused on lymphocytes that blur 
traditional boundaries between innate and adaptive immune systems (Figure 1, Criscitiello and de Figueiredo, 2013). The development and functional properties of "innate-like" B and $\mathrm{T}$ cells and natural killer (NK) cells augment understanding of innate lymphoid cells (ILCs; Lanier, 2013).

Invertebrate immunology and plant immunity have benefitted by understanding priming; it may actually be a template for designing future vaccines (Netea, 2013). No longer acceptable that innate is primitive or irreversibly non-specific, we can now achieve a prolonged, enhanced functional state after adequate priming by producing a new strategy: Trained (innate) Immunity (TI). By repetitive exposure or priming, TI can be important in host defense creating vaccine responses to certain diseases (van der Meer et al., 2015). TI results from epigenetic reprogramming of innate immune cells and ensures protective, non-specific effects previously induced by vaccines e.g., BCG, measles and whole-microorganisms (Blok et al., 2015). The inability of innate immunity to reliably build on memory is a main difference with the more durable adaptive immunity. Thus, a lasting state of significantly enhanced innate immunity, i.e., trained immunity can be mediated by prototypical innate immune

\section{REFERENCES}

Bailey, S., Miller, B. J., and Cooper, E. L. (1971). Transplantation immunity in annelids. II. Adoptive transfer of the xenograft reaction. Immunology 21, 81-86.

Blok, B. A., Arts, R. J., van Crevel, R., Benn, C. S., and Netea, M. G. (2015). Trained innate immunity as underlying mechanism for the long-term, nonspecific effects of vaccines. J. Leukoc Biol. 98, 347-356. doi: 10.1189/jlb.5RI0315-096R

Cooper, E. L. (1969). Specific tissue graft rejection in earthworms. Science 166, 1414-1415. doi: 10.1126/science.166.3911.1414

Cooper, E. L. (2010). Evolution of immune systems from self/not self to danger to artificial immune systems (AIS). Phys. Life Rev. 7, 55-78. doi: 10.1016/j.plrev.2009.12.001

Cooper, E. L. (2012). "Adaptive immunity from prokaryotes to eukaryotes: broader inclusions due to less exclusivity?", in Recent Advances in Immunology to Target Cancer, Inflammation and Infections, ed J. Kanwar (InTech). Available online at: http://www.intechopen.com/books/recent-advances-in-immunologyto-target-cancer-inflammation-and-infections/adaptive-immunity-fromprokaryotes-to-eukaryotes-broader-inclusions-due-to-less-exclusivity

Cooper, E. L., Cossarizza, A., Suzuki, M. M., Salvioli, S., Capri, M., Quaglino, D., et al. (1995). Autogeneic but not allogeneic earthworm effector coelomocytes kill the mammalian tumor cell target K562. Cell Immunol. 166, 113-122. doi: 10.1006/cimm.1995.0013

Cooper, E. L., and Roch, P. (1984). Earthworm leukocyte interactions during early stages of graft rejection. J. Exp. Zool. 232, 67-72. doi: 10.1002/jez.1402320109

Cooper, E. L., and Roch, P. (1986). Second-set allograft responses in the earthworm Lumbricus terrestris. Transplantation 41, 514-520. doi: 10.1097/00007890198604000-00019

Cossarizza, A., Cooper, E. L., Suzuki, M. M., Salvioli, S., Capri, M., Gri, G., et al. (1996). Earthworm leukocytes that are not phagocytic and cross-react with several human epitopes can kill human tumor cell lines. Exp. Cell Res. 224, 174-182. doi: 10.1006/excr.1996.0125

Criscitiello, M. F., and de Figueiredo, P. (2013). Fifty shades of immune defense. PLoS Pathog. 9:e1003110. doi: 10.1371/journal.ppat.1003110

Engelmann, P., Cooper, E. L., Opper, B., and Nemeth, P. (2011). Chapter 14 Earthworm innate immune system. Soil. Biol. 24, 229-245. doi: 10.1007/9783-642-14636-7_14

Hostetter, R. K., and Cooper, E. L. (1973). Cellular anamnesis in earthworms. Cell Immunol. 9, 384-392. doi: 10.1016/0008-8749(73)90053-1

Kurtz, J. (2005). Specific memory within innate immune systems. Trends Immunol. 26, 186-192. doi: 10.1016/j.it.2005.02.001 cells i.e., NK cells and monocytes/macrophages, descendants of ancient phagocytes. Immediately practical, phytopathogens threaten food supplies and global food security; invertebrates are popular sources of food for humans and aquatic organisms in the food chain. Understanding pathogenesis and effector biology translates into new facilitating tools essential for developing durable disease resistance (Nejat et al., 2016). This represents an encouraging paradigm change in our concept of immunity and a more bountiful landscape spawned by priming and blurred responses!

\section{AUTHOR CONTRIBUTIONS}

The author confirms being the sole contributor of this work and approved it for publication.

\section{ACKNOWLEDGMENTS}

I acknowledge helpful discussions with Jason Lee, an undergraduate student with respect to Blurring. I also thank Hillary Brown for assistance in preparing the manuscript.

Kvell, K., Cooper, E. L., Engelmann, P., Bovari, J., and Nemeth, P. (2007). Blurring borders: innate immunity with adaptive features. Clin. Dev. Immunol. 2007:83671. doi: 10.1155/2007/83671

Lanier, L. L. (2013). Shades of grey-the blurring view of innate and adaptive immunity. Nat. Rev. Immunol. 13, 73-74. doi: 10.1038/ nri3389

Lemmi, C. A. E., and Cooper, E. L. (1981). Induction of coelomocyte proliferation by xenografts in the earthworm Lumbricus terrestris. Dev. Comp. Immunol. 5, 73-80. doi: 10.1016/0145-305X(81)90010-0

Little, T. J., Hultmark, D., and Read, A. F. (2005). Invertebrate immunity and the limits of mechanistic immunology. Nat. Immunol. 6, 651-654. doi: $10.1038 /$ ni1219

Nejat, N., Rookes, J., Mantri, N. L., and Cahill, D. M. (2016). Plantpathogen interactions: toward development of next-generation diseaseresistant plants. Crit. Rev. Biotechnol. 22, 1-9. doi: 10.3109/07388551.2015. 1134437

Netea, M. G. (2013). Training innate immunity: the changing concept of immunological memory in innate host defence. Eur. J. Clin. Invest. 43, 881-884. doi: 10.1111/eci.12132

Paust, S., and von Andrian, U. H. (2011). Natural killer cell memory. Nat. Immunol. 12, 500-508. doi: 10.1038/ni.2032

Pradeu, T., and Cooper, E. L. (2012). The danger theory: 20 years later. Front. Immunol. 17, 3:287. doi: 10.3389/fimmu.2012.00287

van der Meer, J. W., Joosten, L. A., Riksen, N., and Netea, M. (2015). Trained immunity: A smart way to enhance innate immune defense. Mol. Immunol. 68, 40-44. doi: 10.1016/j.molimm.2015.06.019

Vivier, E., Raulet, D. H., Moretta, A., Caligiuri, M. A., Zitvogel, L., Lanier, L. L., et al. (2011). Innate or adaptive immunity? The example of natural killer cells. Science 331, 44-49. doi: 10.1126/science.1198687

Conflict of Interest Statement: The author declares that the research was conducted in the absence of any commercial or financial relationships that could be construed as a potential conflict of interest.

Copyright (C) 2016 Cooper. This is an open-access article distributed under the terms of the Creative Commons Attribution License (CC BY). The use, distribution or reproduction in other forums is permitted, provided the original author(s) or licensor are credited and that the original publication in this journal is cited, in accordance with accepted academic practice. No use, distribution or reproduction is permitted which does not comply with these terms. 